\title{
Principales medidas impositivas en el Impuesto a la Renta y el Impuesto al Valor Agregado derivadas de la emergencia económica por el covid-19 en el Ecuador
}

\author{
Main tax measures in Income Tax and \\ Value Added Tax derived from the \\ economic emergency by covid-19 in \\ Ecuador
}

\section{Principais medidas tributárias em Imposto de Renda e Imposto sobre Valor Agregado derivadas da emergência econômica da covid-19 no Equador}

Omar Sebastián Cabrera Cabrera*

\begin{abstract}
Abogado con profundización en Derecho Tributario y especialista en Derecho Económico Internacional de la Universidad Externado de Colombia; especialista y magíster en Tributación de la Universidad de los Andes; diplomado en Impuestos de la Facultad de Contaduría Pública de la Universidad Externado. Ha sido docente asistente de Derecho Tributario Internacional en la Universidad Externado de Colombia y en la Universidad de los Andes, e investigador del Centro de Estudios Fiscales Externadista y del Instituto Colombiano de Derecho Tributario. Ganador del premio yIN de la IFA Capítulo Colombia 2018, y ganador del Premio Internacional de Investigación Tributaria de IFA Latam 2020. Ha realizado publicaciones en medios nacionales e internacionales en materia de tributación internacional; cuenta con experiencia en consultoría y planeación tributaria nacional e internacional; consultor tributario en PricewaterhouseCoopers Colombia. Las opiniones expresadas en el artículo son personales y solo comprometen al autor. omar. cabrera@uexternado.edu.co / https://orcid.org/0000-0003-4670-0822 DOI: https://doi.org/10.18601/16926722.n18.07
\end{abstract}




\title{
Resumen
}

En este artículo se analizan las medidas tributarias sustanciales en el impuesto a la renta e impuesto al valor agregado, sin tener en cuenta temas de procedimiento o cumplimiento tributario, implementadas recientemente en el Ecuador por motivo de la emergencia sanitaria originada por el covid-19.

Palabras clave: covid-19; medidas tributarias; impuesto sobre la renta; impuesto al valor agregado; Ecuador; emergencia sanitaria.

\begin{abstract}
The present text is intended to carry out a detailed count of the substantial tax measures in the Income Tax and Value Added Tax, without taking into account issues of tax procedure or compliance, recently implemented in Ecuador due to the health emergency originated from the Covid-19.
\end{abstract}

Key words: Covid-19; tax measures; income tax; value added tax; Ecuador; health emergency.

\section{Resumo}

O presente texto destina-se a realizar uma contagem detalhada das medidas tributárias substanciais no Imposto de Renda e no Imposto sobre Valor Agregado, sem levar em conta questões de procedimento ou conformidade tributária, implementadas recentemente no Equador devido a emergências sanitárias originários do Covid-19.

Palavras-chave: Covid-19; Medidas tributárias; Imposto de renda; Imposto sobre valor agregado, Equador e Emergência em saúde. 


\section{Introducción}

La rápida expansión del covid-19 en el mundo derivó en la implementación de distintos tipos de medidas para mitigar su expansión, con miras principalmente a proteger la salud de la población de los Estados, dentro de las cuales se encuentran el cierre de fronteras de todo tipo y los aislamientos obligatorios de la ciudadanía, entre otras.

Naturalmente, esta puesta en marcha de aislamientos obligatorios por parte de los Estados, y voluntarios por parte de las personas en sus hogares, ha generado significativas dificultades económicas para los países. Como era de esperarse, los empleos formales e informales pagaron la cuota más alta, máxime por el alto costo generado por el cierre de restaurantes, fábricas, locales comerciales, etc.

Bajo este escenario, la desaceleración de la industria y de la economía tuvo un efecto nefasto para el mercado internacional de commodities, que se manifestó en la baja demanda de estos y, por dicho motivo, en una mengua sustancial en sus precios de referencia en los mercados internacionales en los cuales son ofrecidos.

Desde la perspectiva latinoamericana, la cotización internacional de estos bienes supone una importancia primordial en el tamaño del ingreso fiscal y corriente de los países de la región. Por ende, este bajonazo en la producción y comercialización ha generado importantes huecos fiscales en las finanzas públicas de los países del área Latam, sin excepción alguna.

Como era de esperarse por la enseñanza histórica, la respuesta lógica con la finalidad de sortear este tipo de crisis fiscal es mediante maniobras de tipo impositivo, de lo cual ya se evidencia un sinnúmero de medidas de naturaleza tributaria a lo largo y ancho del continente, que procuran una búsqueda de aumento en el recaudo, para así poder tener caja y financiar los altos costos de recursos asociados a contrarrestar los efectos de la pandemia.

Claramente, el Ecuador no ha sido ajeno a esta realidad, principalmente por su gran dependencia financiera de las rentas por la explotación de hidrocarburos, tomando como punto de partida las caídas estrepitosas que han tenido el BRENT ${ }^{1}$ y el West Texas Intermediate (WTI). Así las cosas, actualmente se han tomado distintas medidas fiscales en ese país, en aras de combatir la crisis.

Hechos los comentarios introductorios, valga señalar que el presente texto tiene la intención de realizar un recuento pormenorizado de las medidas tributarias sustanciales en el impuesto a la renta y el impuesto al valor agregado, sin tener en cuenta temas de procedimiento o cumplimiento tributario implementadas recientemente en el Ecuador por motivo de la emergencia sanitaria originada por el covid-19. 


\section{Impuesto a la renta}

\section{A. Decreto Legislativo 1021 de 2020}

Mediante el Decreto Legislativo 1021 de 27 de marzo de 2020, expedido por el presidente de la República del Ecuador, con ocasión de la declaratoria de emergencia en dicho país ${ }^{2}$, se tomaron medidas de índole fiscal con miras a superar la crisis económica y proteger a la población más vulnerable; valga que decir que la viabilidad del decreto contó con el visto bueno del Ministerio de Finanzas, teniendo en cuenta las competencias del artículo 74 del Código Orgánico de Planeación y Finanzas Públicas.

Así las cosas, el artículo 1 de dicho decreto, tomando en consideración la facultad reglamentaria del presidente según el artículo 7 del Código Tributario del Ecuador, agrega un nuevo artículo al Reglamento para la Aplicación de la Ley de Régimen Tributario Interno (Decreto 374 de 28 de febrero de 2015) en la parte que corresponde al capítulo X de la resolución, la cual regula las disposiciones generales aplicables a los agentes de retención en la fuente en Ecuador.

De esta manera, se adiciona el artículo 92-1 al reglamento, mediante el cual se crea un mecanismo de autorretención en la fuente para cierto tipo de contribuyentes, que es aplicable a partir del 1 de abril de 2020, el cual aplica sobre la totalidad de los ingresos gravados obtenidos durante el mes respectivo, dado que serán fijados los plazos mensuales de declaración y pago señalados en el artículo 102 del reglamento, los cuales son los siguientes teniendo en cuenta el noveno dígito del número del Registro Único de Contribuyentes (RUC) (tabla 1).

Tabla 1. Plazos de declaración y pago

\begin{tabular}{|c|c|}
\hline Si el noveno dígito es & Fecha de vencimiento (hasta el día) \\
\hline 1 & 10 del mes siguiente \\
\hline 2 & 12 del mes siguiente \\
\hline 3 & 14 del mes siguiente \\
\hline 4 & 16 del mes siguiente \\
\hline 5 & 18 del mes siguiente \\
\hline 6 & 20 del mes siguiente \\
\hline 7 & 22 del mes siguiente \\
\hline 8 & 24 del mes siguiente \\
\hline 9 & 26 del mes siguiente \\
\hline 0 & 28 del mes siguiente \\
\hline
\end{tabular}

Fuente: Registro Único de Contribuyentes (RUC). 
Sin embargo, debe tenerse en cuenta que, cuando la fecha de vencimiento de la declaración coincida con días de descanso obligatorio o feriados, el vencimiento será en el siguiente día hábil; de igual manera, hay que resaltar que los contribuyentes cuyo domicilio principal esté localizado en la provincia de Galápagos podrán presentar la declaración respectiva hasta el día 28 del mes que sigue, sin tener en consideración el noveno dígito del RUC.

De otro lado, estas autorretenciones se podrán acreditar como créditos tributarios contra el impuesto de renta por pagar del respectivo agente de retención; asimismo, se dispone que, para estos casos particulares, el comprobante de retención será emitido a nombre del propio agente de retención. Sobre este último punto, téngase presente que, por virtud de la Resolución NAC-DGERCGC20-00000027 del 6 de abril de 2020, los sujetos pasivos que emitan comprobantes de retención electrónicos entre el lapso del 1 al 6 de abril de 2020 podrán enviarlos electrónicamente al Servicio de Rentas Internas del Ecuador (SRI) entre el 07 y el 13 del respectivo mes y año, por una única vez.

En lo que concierne a quienes aplica esta nueva normativa y la tarifa de retención en la fuente debida, en tabla 2 se detalla dicha información.

TABLA 2. TiPo DE CONTRIBUYENTE Y TARIFA DE RETENCIÓN EN LA FUENTE

\begin{tabular}{|l|c|}
\hline \multicolumn{1}{|c|}{ Contribuyente } & Tarifa de retención (\%) \\
\hline Instituciones financieras sometidas a la vigilancia de la Superintendencia de Bancos & \multirow{2}{*}{1,75} \\
\hline Empresas privadas que prestan el servicio de telefonía móvil & \\
\cline { 1 - 2 } $\begin{array}{l}\text { Empresas que tengan suscritos con el Estado contratos para la exploración y explotación } \\
\text { de hidrocarburos, bajo cualquier modalidad contractual o contratos de obras y servicios } \\
\text { específicos conforme a la Ley de Hidrocarburos o de servicios petroleros complementarios }\end{array}$ & \multirow{2}{*}{1,5} \\
\hline Empresas de transporte de crudo & \\
\hline
\end{tabular}

Fuente: elaboración propia.

\section{B. Resolución NAC-DGERCGC20-00000020}

El SRI, mediante la Resolución NAC-DGERCGC20-00000020 de 20 de marzo de 2020³, realizó modificaciones a la Resolución NAC-DGERCGC14-00787 de 30 de septiembre de 2014 respecto del aumento de la tarifa de retención en la fuente en el impuesto a la renta a algunos tipos de pagos.

Dicho esto, el artículo único de la Resolución NAC-DGERCGC20-00000020 de 2020 consagra dos cambios en materia de retención en la fuente. El primero es la modificación al literal d) del numeral 2 de la Resolución NAC-DGERCGC14-00787 de 30 de septiembre de 2014, y el segundo es el aumento del porcentaje de retención del 1 al 1,75\% respecto de los pagos o créditos en cuentas por transferencias de todo tipo de bienes muebles de naturaleza corporal. 
Por su parte, se debe resaltar que, de acuerdo con la información suministrada por el SRI (2020) y los medios de comunicación locales (Sandoval, 2020), la modificación a estas reglas de retención en la fuente del impuesto a la renta podría representar un recaudo adicional cercano a los US\$426 millones en los 8 meses restantes del año 2020, lo que, sin lugar a duda, generará liquidez a la caja fiscal del Estado ecuatoriano.

\section{Cambios al literal d) Del numeral 2 de la Resolución NAC- DGERCGC14-00787 DE 30 DE SEPTIEMBRE DE 2014}

A continuación, en la tabla 3, se hace un comparativo entre la nueva regulación modificatoria del literal d) del numeral 2 de la Resolución NAC-DGERCGC14-00787 de 30 de septiembre de 2014 y la existente previa a la expedición de la Resolución NAC-DGERCGC20-00000020 de 20 de marzo de 2020.

\section{Tabla 3. Comparativo entre la REgUlaCión MODIFiCATORIA DEL Literal D) DEL NUMERAL 2 DE LA RESOLuCión NAC-DGERCGC14-00787 y LA EXISTENTE PREVIA A LA EXPEDICIÓN de LA RESOLUCIÓN NAC-DGERCGC20-00000020}

\begin{tabular}{|c|c|}
\hline Antigua redacción & Nueva redacción \\
\hline $\begin{array}{l}\text { “d) Adquisición de todo tipo de bienes muebles de natu- } \\
\text { raleza corporal, así como los de origen agrícola, avícola, } \\
\text { pecuario, apícola, cunícola, bioacuático y forestal. Se ex- } \\
\text { ceptúan la compra de combustible, y aquellos que la nor- } \\
\text { mativa tributaria vigente lo establezca de manera expresa. } \\
\text { Adicionalmente se exceptúan los pagos por concepto de } \\
\text { adquisición local de banana a productores, al encontrarse } \\
\text { dichos pagos sujetos al porcentaje de retención estable- } \\
\text { cido en la Ley de Régimen Tributario Interno y su Regla- } \\
\text { mento de Aplicación; no asílos pagos para la adquisición } \\
\text { local de la fruta a personas distintas de productores de } \\
\text { banana en cuyo caso aplica el porcentaje de retención } \\
\text { establecido en el presente numeral”.(énfasis agregado) }\end{array}$ & $\begin{array}{l}\text { "d) Adquisición de bienes de origen agrícola, avícola, pe- } \\
\text { cuario, apícola, cunícola, bioacuáticos, forestal y carnes, } \\
\text { que se mantengan en estado natural conforme lo señalado } \\
\text { en la Ley de Régimen Tributario Interno, se aplicará el } \\
\text { porcentaje de retención previsto en este numeral inde- } \\
\text { pendientemente de que se emita factura o liquidación de } \\
\text { compra de bienes o prestación de servicios; esto también } \\
\text { aplica a los ingresos de producción y comercialización } \\
\text { local de actividades agropecuarias señalados en el artículo } \\
27.1 \text { de la referida Ley. } \\
\text { No estará sujeta a retención la compra de combustible, } \\
\text { ni aquellos pagos sobre los que la normativa tributaria } \\
\text { vigente lo establezca de manera expresa" }\end{array}$ \\
\hline
\end{tabular}

Fuente: elaboración propia.

Como se observa en la tabla 3 , se mantiene la retención para los productos de origen agrícola, avícola, pecuario, apícola, cunícola, bioacuáticos y forestal, pero se agregó el de carnes. De la misma forma, también se incluyó el requisito de que se trate de productos en estado natural y que la retención se aplica independientemente de si se emite o no factura o liquidación de compra de bienes.

Empero, tomando como partida la parte resaltada de la tabla, es preciso indicar que se estableció que la retención en la fuente también será aplicable a todas las actividades 
agropecuarias domésticas consagradas en el artículo 27.1 de la Ley de Régimen Tributario $^{4}$, el cual se refiere a las actividades del sector bananero local.

De todas maneras, vale aclarar que se mantuvo la regla de la exención de retención en la fuente del Impuesto de Renta respecto a la compra de combustible y de los demás casos de exoneración de esa obligación de retención que establezca la ley tributaria.

Finalmente, resulta relevante indicar que para estas circunstancias descritas en la nueva redacción de la norma se mantiene la tarifa nominal del $1 \%$ prevista antes de la emergencia por el covid-19.

\section{AuMENTO EN EL PORCENTAJE DE RETENCIÓN EN LA FUENTE}

El literal b) del artículo único de la Resolución NAC-DGERCGC20-00000020 de 20 de marzo de 2020 aumentó la alícuota retención en la fuente por la adquisición de bienes muebles corporales, así: “2.1. Están sujetos a la retención del 1,75\% los pagos o acreditaciones en cuenta por la adquisición de todo tipo de bienes muebles de naturaleza corporal".

No obstante, es fundamental tener en cuenta que este cambio resulta relevante también para otros tipos de pagos en la medida en que a los pagos a compañías de seguro y reaseguros $^{5}$, pagos por arrendamiento mercantil ${ }^{6}$, pagos a medios de comunicación ${ }^{7}$ y pagos por

4 Dicho artículo 27 señala que: "Impuesto a la renta único para las actividades del sector bananero. - Los ingresos provenientes de la producción, cultivo, exportación y venta local de banano según lo previsto en este artículo, incluyendo otras musáceas que se produzcan en Ecuador, estarán sujetos a un impuesto a la renta único conforme a las siguientes disposiciones: 1 . Venta local de banano producido por el mismo sujeto pasivo. En este caso la tarifa será de hasta el $2 \%$ del valor de facturación de las ventas brutas, el que no se podrá calcular con precios inferiores al precio mínimo de sustentación fijado por la autoridad nacional de agricultura. La tarifa podrá modificarse mediante decreto ejecutivo, misma que podrá establecerse por segmentos y entrará en vigencia a partir del siguiente periodo fiscal de su publicación, dentro de un rango de entre el 1,25\% y el 2\%. Esta tarifa podrá ser reducida hasta el $1 \%$ para el segmento de micro productores y actores de la economía popular y solidaria cuyos montos de ingresos brutos anuales no superen el doble del monto de ingresos establecido para la obligación de llevar contabilidad".

$5 \quad$ El artículo 118 del Reglamento de la Ley de Renta señala que: "Pagos a compañías de seguros y reaseguros. - Los pagos o créditos en cuenta que se realicen a compañías de seguros y reaseguros legalmente constituidas en el país y a las sucursales de empresas extranjeras domiciliadas en el Ecuador, están sujetos a la retención en un porcentaje similar al señalado para las compras de bienes muebles aplicable sobre el $10 \%$ de las primas facturadas o planilladas".

$6 \quad$ El artículo 119 del Reglamento de la Ley de Renta señala que: "Retención por arrendamiento mercantil. - Los pagos o créditos en cuenta que se realicen a compañías de arrendamiento mercantil legalmente establecidas en el Ecuador, están sujetos a la retención en un porcentaje similar al señalado para las compras de bienes muebles, sobre los pagos o créditos en cuenta de las cuotas de arrendamiento, inclusive las de opción de compra".

7 El artículo 120 del Reglamento de la Ley de Renta señala que: "Pagos a medios de comunicación. - Los pagos o créditos en cuenta por facturas emitidas por medios de comunicación y por las agencias de publicidad, están sujetas a retención en la fuente en un porcentaje similar al determinado para las compras de bienes muebles; a su vez, las agencias de publicidad retendrán sobre los pagos que realicen a los medios de comunicación, el mismo porcentaje sobre el valor total pagado". 
actividades de construcción o similares ${ }^{8}$, se les aplica por defecto la retención del 1,75\% de bienes muebles corporales.

Como complemento, esta nueva normativa también incrementó del 2 al 2,75\% el porcentaje de retención en la fuente aplicable a todos aquellos pagos o créditos en cuenta que no poseen alícuotas específicas de dicha retención.

Hechos los comentarios anteriores, en la tabla 4 se resumen los cambios en la tarifa de retención en la fuente de los pagos antes referidos.

Tabla 4. Cambios en la tarifa de retención en la fuente para pagos o créditos EN CUENTA QUE NO POSEEN ALÍCUOTAS ESPECÍFICAS

\begin{tabular}{|l|c|c|}
\hline \multicolumn{1}{|c|}{ Concepto } & $\begin{array}{c}\text { Tarifa de retención anterior } \\
(\mathbf{\%})\end{array}$ & $\begin{array}{c}\text { Tarifa de retención nueva } \\
(\boldsymbol{\%})\end{array}$ \\
\hline $\begin{array}{l}\text { Adquisición de todo tipo de bienes muebles de } \\
\text { naturaleza corporal }\end{array}$ & 1 & 1,75 \\
\hline Pagos a compañías de seguros y reaseguros & 1 & 1,75 \\
\hline Pagos por arrendamiento mercantil & 1 & 1,75 \\
\hline Pagos a medios de comunicación & 1 & 1,75 \\
\hline $\begin{array}{l}\text { Pagos por actividades de construcción o } \\
\text { similares }\end{array}$ & 1 & 1,75 \\
\hline $\begin{array}{l}\text { Adquisición de bienes de origen agrícola, aví- } \\
\text { cola, pecuario, apícola, cunícola, bioacuáticos, } \\
\text { forestal y carnes }\end{array}$ & 1 & 1 \\
\hline $\begin{array}{l}\text { Pagos o créditos en cuenta que no contemplan } \\
\text { un porcentaje específico de retención en la } \\
\text { fuente }\end{array}$ & 2 & 2,75 \\
\hline
\end{tabular}

Fuente: elaboración propia.

\section{Ley Orgánica de Apoyo Humanitario para combatir la crisis sanitaria derivada del covid-19}

Bajo el marco de la emergencia, en los días 13, 14 y 15 de mayo de 2020, la Asamblea Nacional de Ecuador debatió un proyecto de ley orgánica para reactivar la economía del país, denominada Ley Orgánica de Apoyo Humanitario para combatir la crisis sanitaria derivada del covid-19, la cual fue aprobada pero aún no ha sido promulgada por el presidente, según los procedimientos legales internos, e incluso apartes de su articulado fueron objetados por el Ejecutivo mediante Oficio T 580-SGJ-20-0189 de 9 de junio de 2020. 
Dicho esto, a continuación se analizarán los puntos tributarios más relevantes de esta nueva normativa preliminar, junto con las objeciones presidenciales, sin perjuicio de mencionar que esta última toca bastantes puntos más allá de lo fiscal.

\section{CONTRIBUCIONES SOLIDARIAS}

El texto original del proyecto de ley presentado por el Órgano Ejecutivo contemplaba la creación de un par de contribuciones tributarias temporales dirigidas a aumentar el recaudo. Dicho esto, se incluía una contribución aplicable a las personas naturales asalariadas, ya fueran del sector público o privado, sobre una base progresiva aplicable al ingreso neto mensual.

Igualmente, se creaba una contribución humanitaria sobre las utilidades de las sociedades a una tarifa plana del $5 \%$ sobre la cifra mayor entre la utilidad gravable y la utilidad disponible para distribución de 2018, siempre que esta hubiese sido igual o superior a la base de US\$1.000.000.

Sin embargo, es importante hacer hincapié en que estas dos contribuciones no fueron finalmente aprobadas en el texto definitivo y, por ende, no tienen aplicación alguna, aunque se reseñan a fin de ofrecer un mayor contexto de la evolución normativa generada por el covid-19.

\section{CRÉditos PRODUCTIVOS PARA LA REACTIVACIÓN ECONÓMICA Y PROTECCIÓN DEL EMPLEO EN EL SECTOR PRIVADO}

El artículo 10 de la Ley de Apoyo Humanitario establece una deducción especial para las entidades financieras del sistema nacional que otorguen créditos ordinarios, productos o microcréditos a entidades que sean pequeñas y medianas empresas (Mipymes), entre abril y diciembre de 2020 .

Para que sea aplicable el beneficio, el crédito debe ser superior a US $\$ 25.000$ y debe otorgarse por un periodo de mínimo 48 meses; en caso de que el crédito sea de corto plazo, es decir, de menos de un año, y por montos superiores a los US $\$ 10.000$, es posible aumentar el plazo de este primero a mínimo dos años para también tener derecho a la deducción en mención.

Ahora bien, el beneficio consiste en la prerrogativa impositiva de tomar como gasto deducible el $50 \%$ del valor de los intereses pagados por las Mipymes a la entidad bancaria debido al crédito otorgado, siempre que cumpla con los anteriores requisitos.

Por último, frente a las objeciones hechas por el poder administrativo ecuatoriano a este artículo, en primera medida, se busca eliminar la referencia a las Mipymes a efectos del derecho a tomar la deducción, con lo cual el beneficio se haría extensivo a más tipos de deudores. Segundo, se pretende agregar un párrafo mediante el cual se levanta la obligación del pago de la contribución establecida en el artículo 14 del Código Orgánico Monetario y Financiero, respecto de créditos refinanciados, reprogramados o reestructurados 
según esta nueva normativa. Tercero, se hace claridad al agregar unas líneas para precisar que el órgano de control de las Mipymes será la Superintendencia de Economía Popular y Solidaria. Cuarto, y de suma importancia, se prevé una regla en virtud de la cual, los créditos de más de US\$10.000 y cuyo plazo se aumente a por lo menos 12 meses sobre el plazo inicial, estarán exentos del pago del $50 \%$ de los intereses del impuesto a la renta devengados con ocasión de estas deudas. Quinto, se incluye un inciso que señala que el Estado ecuatoriano complementará los esfuerzos crediticios con sus propios mecanismos de liquidez, crédito, seguros o garantías orientados a sostener el tejido productivo y, en consecuencia, el empleo en el país.

\section{DEDUCCIÓN POR GASTOS DE TURISMO}

La cláusula decimotercera de la Ley de Apoyo Humanitario establece que las personas naturales tendrán derecho a deducir, por los años 2020 y 2021, los gastos incurridos por motivo de turismo interno en el Ecuador, en un monto igual a las categorías vigentes. Sin embargo, esta disposición señala que el SRI debe emitir la reglamentación general para cumplir con dicha medida.

No obstante, una vez analizada la objeción hecha por el presidente a esta disposición, debe decirse que esta última pretende agregar una aclaración indicando que este derecho de deducción estará en cabeza de cualquier persona natural sin importar que supere el monto de ingresos netos fijados en la ley, en un monto igual a las categorías vigentes.

\section{Impuesto al valor agregado (IVA)}

Respecto a medidas en IVA, consideramos de vital importancia hacer hincapié en que la gran mayoría de medicamentos y drogas de uso humano, junto con los servicios de salud, están a tarifa 0 del impuesto. Dicho esto, el artículo 55 de la Ley de Régimen Tributario Interno señala que:

6. Medicamentos y drogas de uso humano, de acuerdo con las listas que mediante Decreto establecerá anualmente el presidente de la República, así como la materia prima e insumos importados o adquiridos en el mercado interno para producirlas. En el caso de que por cualquier motivo no se realice las publicaciones antes establecidas, regirán las listas anteriores.

Ahora bien, mediante el Decreto 1151 de 18 de junio de 2008 se había regulado la exención de IVA para medicamentos antes señalada, en donde se había establecido una lista taxativa de todas las medicinas a las cuales les era aplicable el beneficio.

Sin embargo, por motivos de simplicidad y eficiencia, mediante el Decreto 1219 de 29 de julio de 2008 se eliminó el sistema de la lista y, por tanto, se adoptó un mecanismo general de no causación de IVA en medicamentos incluso cuando son importados. 
Asimismo, el artículo 56 de esta norma en cuestión también excluye del IVA los servicios médicos: "2. Los de salud, incluyendo los de medicina prepagada y los servicios de fabricación de medicamentos".

Por añadidura, es relevante resaltar que, según los numerales 1, 2, 3 y 4 del artículo 56 de esta disposición, la gran mayoría de productos agrícolas y alimentos para uso humano no causan IVA.

Como se observa, los elementos y servicios médicos para hacerle frente a la pandemia, así como también la generalidad de los alimentos de consumo humano, actualmente no tienen IVA en el Ecuador.

Sin embargo, todavía no se ha planteado la alternativa de hacer algún tipo de reducción transitoria a la tarifa general de IVA en este país o nuevas exclusiones al impuesto, con lo cual es justo decir que son pocas o casi nulas las medidas tomadas en torno a esta imposición indirecta.

\section{Conclusiones}

No se discute el hecho de que el advenimiento de la pandemia del covid-19 ha generado serios problemas en materia económica y dificultades de recaudo fiscal. Como era de esperarse, la región de Latinoamérica no ha sido ajena a esta realidad, e incluso ha sido una de las zonas más vulnerables a la recesión económica.

Bajo este panorama, las finanzas públicas de Ecuador se han visto seriamente afectadas, aunque principalmente esto se ha debido al bajón sustancial en los precios internacionales del crudo. Esto llevó a que este país, así como muchos otros Estados más en distintas partes del mundo, recurrieran a la implementación inmediata de medidas tributarias extraordinarias y urgentes, con miras a aumentar el recaudo y así mejorar la caja.

De esta manera, a través de medidas normativas, el Ejecutivo ecuatoriano se vio forzado a implementar nuevas retenciones en la fuente en el impuesto sobre la renta y aumentar las tarifas de algunas ya existentes, e incluso crear autorretenciones especiales en la fuente para ciertos tipos de contribuyentes, a fin de poder anticipar la recaudación del impuesto y, de esta manera, lograr atender los gastos originados por la emergencia sanitaria.

Igualmente, la Asamblea Nacional de Ecuador aprobó un proyecto de ley que, entre otros tipos de medidas, da alivio tributario a los intereses derivados de ciertos créditos productivos empleados para mejorar la situación económica del país, e igualmente se agregan disposiciones fiscales de deducción de gastos en turismo local para estimular ese sector tan afectado por las medidas de aislamiento, aunque falta esperar la legislación definitiva luego de las objeciones presidenciales. De otro lado, es preciso hacer hincapié en que en materia de IVA no se han tomado mayores medidas.

En definitiva, todas estas medidas eran necesarias en el marco de la situación del covid-19, aunque es preciso señalar que se podrían poner en marcha otras medidas de alivio fiscal para algunos sectores o una reducción en la tarifa de IVA, tal como está pasando en otras jurisdicciones. 


\section{Referencias}

Sandoval, P. (2020, 12 de marzo). SRI emite resolución que generará \$ 426 millones a la caja fiscal. El Universo. https:/www.eluniverso.com/noticias/2020/03/12/ nota/7778907/sri-emite-resolucion-que-generara-426-millones-caja-fiscal

SRI (2020, 12 de marzo). Cambio en porcentajes de retención de impuesto a la renta busca generar mayor flujo de ingresos. https:/www.sri.gob.ec/web/guest/ detalle-noticias?idnoticia $=728 \&$ marquesina $=1$

\section{Jurisprudencia}

Código Tributario del Ecuador.

Decreto 1151 de 18 de junio de 2008.

Decreto 1219 de 29 de julio de 2008.

Decreto 37428 de febrero de 2015.

Decreto Ejecutivo 101716 de marzo de 2020.

Decreto Legislativo 102127 de marzo de 2020.

Oficio No. T 580-SGJ-20-0189 9 de junio de 2020.

Ley Orgánica de Apoyo Humanitario para combatir la crisis sanitaria derivada del COVID-19 de 22 de junio de 2020.

Resolución NAC-DGERCGC14-00787 de 30 de septiembre de 2014.

Resolución NAC-DGERCGC20-00000020 de 20 de marzo de 2020.

Resolución NAC-DGERCGC20-00000027 de 6 de abril de 2020.

Fecha de recepción: 15 de junio de 2020.

Fecha de aprobación par 1: 04 de julio de 2020.

Fecha de aprobación par 2: 14 de julio de 2020. 